\title{
Assessment of female sexual function in remote postpatum period: a cross- sectional study
}

Thalita Rodrigues Christovam Pereira 1

Elissa Hanayama Dottori 2

Flávia Maciel de Aguiar Fernandes Mendonça 3

Ana Carolina Sartorato Beleza 4

\footnotetext{
1 Programa de Pós-graduação Interdisciplinar em Ciências da Saúde. Universidade Federal de São Paulo (UNIFESP). Rua Silva Jardim, 136. Vila Mathias. Santos, SP, Brasil. CEP: 11015-020. E-mail: thalita.christovam@gmail.com

2 Programa de Pós-graduação em Reeducação Funcional da Postura e do Movimento. Universidade de São Paulo. São Paulo, SP, Brasil.

${ }^{3}$ Instituto Geração Mãe. Ribeirão Preto, SP, Brasil.

${ }_{4}^{4}$ Departamento de Fisioterapia. Universidade Federal de São Carlos. São Carlos, SP, Brasil.
}

\begin{abstract}
Objectives: (i) to evaluate female sexual function in remote postpartum period within Brazilian women and (ii) to compare female sexual dysfunction in relation to the mode of delivery.

Methods: in this cross-sectional study, two groups of remote postpartum women, who underwent vaginal delivery $(n=30)$ and cesarean $(n=48)$, were studied. The sexual function of participants was assessed through an online Brazilian version of FSFI between 45 and 180 days after delivery. Data were analyzed by descriptive and inferential statistics using Fisher exact test, and Student t test.

Results: based on the data of 78 women who completed the online questionnaire, $78 \%$ $(n=61)$ showed sexual dysfunction on remote postpartum period being that the FSFI mean score for vaginal postpartum was 22.17 and for cesarean postpartum, $21.12(p=0.443)$.

Conclusions: the majority of remote postpartum women showed sexual dysfunction. There was no significant difference found on female sexual function between modes of delivery.

Key words Cesarean section, Natural childbirth, Postpartum period, Sexual health, Women's health
\end{abstract}




\section{Introduction}

During postpartum period, women experience a wide variety of hormonal, physical and emotional changes that can affect their well-being, partnership and sexuality. ${ }^{1}$ Thus, this period is vulnerable to the onset of sexual dysfunction. Sexuality problems like low sexual desire, arousal, lubrication and difficulty to reach orgasm can be associated with postpartum hormonal status. ${ }^{2}$ Furthermore, breastfeeding stimulates secretion of prolactin which suppresses libido. ${ }^{3}$ In addition, psychological factors can be involved, like depression, anxiety, ${ }^{1}$ body dissatisfaction, parenting stress and fatigue. ${ }^{2}$ Other points like sleepless nights, baby care and waiting for medical permission 4 can also contribute to inhibition of the sexual response cycle.

Vaginal delivery has as main feature the involvement of the pelvic floor muscles which play an important role for sexual pleasure. Physical changes in female genitalia caused by childbirth, perineal trauma and pain experience during intercourse are frequently reported in literature.2,3,5 However, vaginal delivery is known as advantageous for both maternal and neonatal health. Perineal complications during childbirth both can be avoided with Physiotherapy intervention in prenatal preparation and recovered on postpartum period.

On cesarean there is no change on perineum for fetus output, 6 but all experienced changes during pregnancy can be added to other factors like discomfort on operation section, consequently influencing negatively sexual function. The rates of cesarean in Brazil are increasing 7 and, consequently, more adverse effects for both postpartum women and baby has been observed. 8,9

The sexual function may be a factor influencing women's choice of mode of delivery.2,6 On the last decade, some studies have investigated sexual function of postpartum women according to the mode of delivery. Previous evidence suggested that elective cesarean and vaginal delivery with an intact perineum protect female sexuality. ${ }^{3}$ However, a recent review 10 showed that there is no clear evidence of an association between mode of delivery and changes in sexual function.

Although this theme has been increasingly studied around the world, little has been investigated on Brazilian puerperal population. Thus, investigating the relationship between mode of delivery and sexual function during remote postpartum period among Brazilian women is important in order to consider the particularities about this population and their health context and, hence, to plan health care management.

Therefore, the objectives of this study were (i) to evaluate the female sexual function in remote postpartum period in Brazilian women and (ii) to compare the female sexual dysfunction in relation to the mode of delivery.

\section{Methods}

This cross-sectional study was approved by Ethics Committee of the Federal University of São Paulo under protocol 786,227/2014. The recruitment of volunteers occurred via dissemination in virtual media (website for pregnant and postpartum women, social networks and e-mail).

Brazilian women in remote postpartum (between 45 and 180 days after childbirth) were included in this study, age range 18-35 years, literate, able to understand the research instrument, with healthy and single newborn, active sexually in the last four weeks and with a steady partner at the time of evaluation. The exclusion criteria were: puerperal women with over 180 days after childbirth; with new current pregnancy; who were unable to have sex for puerperal complications and who had babies admitted or with risk of death

For data collection, a form was used, with personal, social, cultural and related to pregnancy and puerperal data. The sexual function of participants was assessed through an online Brazilian version of Female Sexual Function Index (FSFI)11 on remote postpartum period.

The FSFI analyzes female sexual function over the last four weeks by means of six domains: sexual desire, arousal, lubrication, orgasm, satisfaction, and pain. The questionnaire is easy to understand, selfadministered and has acceptable statistical validity in the literature. ${ }^{11}$ The FSFI optimal cutoff score is 26.55 , to differentiate women with and without sexual dysfunction. 12 The cutoff score of FSFI was considered the criteria to classify the postpartum women in "with sexual dysfunction" and "without sexual dysfunction" in the present study.

A previous study with online FSFI in Brazilian population 11 presented 7.6 points for standard deviation on total score of the questionnaire. Sample calculation considered a clinical difference of five units on FSFI score, test power of 0.80 and significance level of 0.05 . Thus, the minimum sample size should be 28 women for each group (vaginal postpartum group and cesarean postpartum group).

Data were analyzed by descriptive and inferential statistics. The Fisher exact test was used to obtain the association between categorical variables 
and the type of delivery. Student $t$ test for unrelated samples was used to check whether there was difference between the study groups regarding the variables: time to return to sexual activity, domains (sexual desire, arousal, lubrication, orgasm, satisfaction, and pain) and FSFI total score. The level of significance used for every comparison was $5 \%$ $(p \leq 0.05)$.

\section{Results}

Eighty-three puerperal women completed the online questionnaire. Of these, 5 women were excluded because they are over 180 days after childbirth. Among the included women, 30 have gone through vaginal delivery and 48 by cesarean. Table 1 shows the profile characteristics of participants.

During pregnancy, $35.9 \%(n=28)$ of postpartum women reported having had some sexual complications, being $30 \%(n=9)$ belonging to vaginal postpartum and $39.6 \%(n=19)$ to cesarean postpartum. Among the cited complications were "pain", "low libido", "fear" and "fatigue".

Among the participants, 91\% $(n=71)$ had some type of complaint on postpartum period. Of these, $59.2 \%(\mathrm{n}=42)$ were from cesarean postpartum, while $40.8 \%(n=29)$ from vaginal postpartum. Table 2 below shows the complaints reported by participants according to the mode of delivery.
Perineal trauma was reported by $53.3 \%(n=16)$ of participants from vaginal postpartum. During remote postpartum, $21.8 \%(n=17)$ of participants practiced some exercise, being $20 \%(n=6)$ from vaginal postpartum and $22.9 \%(\mathrm{n}=11)$ from cesarean postpartum, $(p=0.999)$.

In relation to menstrual cycle, $32.1 \%(n=25)$ of the women returned to menstruate, being $33.3 \%$ $(\mathrm{n}=10)$ participants from vaginal postpartum and $31.5 \%(n=15)$ from cesarean postpartum. Among the participants, $74.4 \%(n=58)$ reported taking a contraceptive, being $73.3 \%(n=22)$ from vaginal postpartum and $75 \%(n=36)$ from cesarean postpartum.

All participants reported having returned to sexual activity. The mean time to return to sexual activity was $52.83( \pm 20.4)$ days after vaginal delivery and $52.94( \pm 19.88)$ days after cesarean. Sexual dysfunction was present in $78.2 \%(n=61)$ of the study participants. Table 3 shows the comparison of each domain and the total FSFI score between modes of delivery.

Figure 1, below, illustrates the total score obtained by the FSFI according to mode of delivery. Women from vaginal postpartum had a median of 22.45 FSFI total score, while women from cesarean postpartum had a median of 21.9 FSFI total score.

Table 1

\begin{tabular}{|c|c|c|c|}
\hline Characteristics & Vaginal $(n=30)$ & Cesarean $(n=48)$ & $p$ \\
\hline Age (years), mean (SD) & $30.17( \pm 4.69)$ & $30.04( \pm 3.75)$ & 0.902 \\
\hline Time of puerperium (days), mean (SD) & $110.7( \pm 42.4)$ & $127.9( \pm 43.1)$ & 0.948 \\
\hline \multicolumn{4}{|l|}{ Race, $\mathrm{n}(\%)$} \\
\hline White & $23(76.7)$ & $38(9.2)$ & \\
\hline Brown & $4(13.4)$ & $7(14.6)$ & \\
\hline Black & $1(3.3)$ & $2(4.2)$ & 0.861 \\
\hline Asian & $1(3.3)$ & $1(2.0)$ & \\
\hline American indian & $1(3.3)$ & $0(0.0)$ & \\
\hline \multicolumn{4}{|l|}{ Marital status, n (\%) } \\
\hline Married & $23(76.7)$ & $41(85.4)$ & 0.373 \\
\hline Stable union & $7(23.3)$ & $7(14.6)$ & \\
\hline \multicolumn{4}{|l|}{ Schooling, n (\%) } \\
\hline Complete high school & $3(10.0)$ & $6(12.5)$ & \\
\hline Incomplete technical education & $0(0.0)$ & $1(2.1)$ & \\
\hline Complete technical education & $0(0.0)$ & $2(4.2)$ & 0.830 \\
\hline Incomplete higher education & $4(13.3)$ & $4(8.3)$ & \\
\hline Complete higher education & $23(76.7)$ & 35 (72.9) & \\
\hline \multicolumn{4}{|l|}{ Occupation, n (\%) } \\
\hline Paid occupation & $19(63.3)$ & $42(87.5)$ & 0.022 \\
\hline Unpaid occupation & $11(36.7)$ & $6(12.5)$ & \\
\hline \multicolumn{4}{|l|}{ Parity, $\mathrm{n}(\%)$} \\
\hline Primiparous & $19(63.3)$ & $36(75.0)$ & 0.519 \\
\hline Multiparous & $11(36.7)$ & $12(25.0)$ & \\
\hline
\end{tabular}

Fisher exact test; $\mathrm{n}=$ number of participants; $\%=$ percentage of participants; $S \mathrm{D}=$ standard deviation ( \pm ). 
Table 2

Remote postpartum period complaints.

\begin{tabular}{|c|c|c|c|c|c|}
\hline \multirow[t]{2}{*}{ Complaints } & \multicolumn{2}{|c|}{ Vaginal } & \multicolumn{2}{|c|}{ Cesarean } & \multirow[t]{2}{*}{$p$} \\
\hline & $\mathrm{n}$ & $\%$ & $\mathrm{n}$ & $\%$ & \\
\hline Neck pain & 2 & 6.7 & 10 & 20.8 & 0.115 \\
\hline Low back pain & 8 & 26.7 & 19 & 39.6 & 0.329 \\
\hline Upper limbs discomfort & 1 & 3.3 & 8 & 16.7 & 0.142 \\
\hline Lower limbs discomforts & 2 & 6.7 & 8 & 16.7 & 0.301 \\
\hline Perineum discomforts & 24 & 80.0 & 6 & 12.5 & 0.001 \\
\hline Abdominal wound/scar discomforts & - & - & 9 & 18.8 & - \\
\hline Abdominal pain & 2 & 6.7 & 2 & 4.2 & 0.636 \\
\hline Involuntary urine loss & 3 & 10.0 & 1 & 2.1 & 0.292 \\
\hline Involuntary loss of feces & 0 & - & 1 & 2.1 & 0.999 \\
\hline
\end{tabular}

Fisher exact test; $\mathrm{n}=$ number of participants; $\%=$ percentage of participants.

Table 3

Comparison of domains and total score of online Brazilian version of Female Sexual Function Index (FSFI) between mode of delivery.

\begin{tabular}{|c|c|c|c|}
\hline $\begin{array}{l}\text { FSFI domains, mean } \\
\text { (SD) }\end{array}$ & $\begin{array}{c}\text { Vaginal postpartum } \\
\text { scores }\end{array}$ & $\begin{array}{c}\text { Cesarean postpartum } \\
\text { scores }\end{array}$ & $p$ \\
\hline $\begin{array}{l}\text { Sexual desire } \\
\text { Arousal } \\
\text { Lubrication } \\
\text { Orgasm } \\
\text { Satisfaction } \\
\text { Pain } \\
\text { Total Score }\end{array}$ & $\begin{array}{c}2.82( \pm 1.14) \\
3.68( \pm 1.53) \\
4.03( \pm 1.59) \\
3.88( \pm 1.63) \\
4.16( \pm 1.54) \\
3.59( \pm 0.75) \\
22.17( \pm 5.34)\end{array}$ & $\begin{array}{c}2.66( \pm 1.18) \\
3.52( \pm 1.52) \\
3.78( \pm 1.70) \\
3.65( \pm 1.41) \\
4.10( \pm 1.66) \\
3.40( \pm 1.02) \\
21.12( \pm 6.56)\end{array}$ & $\begin{array}{l}0.560 \\
0.664 \\
0.510 \\
0.526 \\
0.872 \\
0.342 \\
0.443\end{array}$ \\
\hline
\end{tabular}

Student t test; $\mathrm{n}=$ number of participants; $\%=$ percentage of participants; SD=standard deviation ( \pm ).

Figure 1

Distribution of FSFI total score (minimum, maximum and median) according to the mode of delivery.

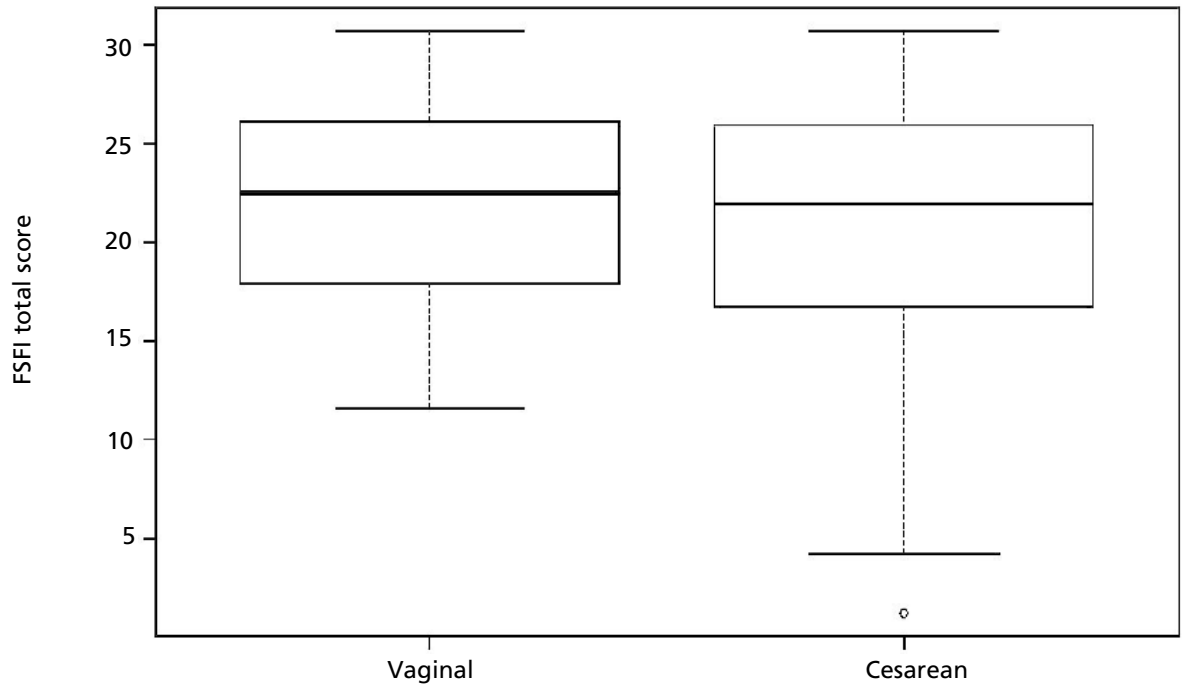

Student t test for unrelated samples $(p=0.443)$ 


\section{Discussion}

The present study showed high frequency of sexual dysfunction among women in remote postpartum period. Sexual dysfunction was independent of mode of experienced childbirth. Sexual desire was the FSFI domain with lowest score, followed consecutively by pain, arousal, orgasm, lubrication and satisfaction.

These findings are in line with previous international surveys data that had reported no sexual function difference between mode of delivery. $3,13,14$

Others authors supported that obstetric intervention on primiparous women might affect negatively the postpartum sexual function. A multicentre prospective cohort study 15 suggests that vacuum extraction and cesarean contribute to persisting dyspareunia which affects a significant proportion of women up to 18 months postpartum period. In addition, other authors 16 concluded that there was no difference on sexual function between women who had vaginal delivery with mediolateral episiotomy and those who experienced cesarean.

According to Qian et al.,17 postpartum sexual function after cesarean has a greater incidence of adverse effects and does not provide long-term protective effects against postpartum stress urinary incontinence. Cesarean postpartum was associated with higher pain levels that persisted at the first 6 months, a higher level of depressive symptoms at 3 months and lower sexual satisfaction at 4-6 weeks more than vaginal postpartum. 18

Sexual function is complex and is affected by many others factors, like lifestyle, interpersonal relationships and cultural conditions. 16 Since the mode of delivery did not influence the results related to sexual function, other issues should be analyzed in this sample.

Pregnancy has a negative impact on female sexual function, particularly on sexual desire and arousal. 19 Women with anxiety and depressive comorbidities, but not those with pure anxiety or pure depression, are in an increased risk of sexual dysfunction during pregnancy and postpartum period, which might interfere with their relationship. ${ }^{1}$

The time taken to sexual intercourse resumption after childbirth depends of determining factors like fear of a new pregnancy, fear of pain, the health professional's discharge, the shame of her own body and changes in libido. 4 Degree of perineal injuries, breastfeeding, maternal age, race, 6 baby care, fatigue also might contribute. Women who experienced severe maternal morbidity delay resumption of sexual activity. ${ }^{20}$ Morbidity on postpartum period influences physical and psychological women's health and consequently might be negative for some female sexual function aspects, such as sexual desire, pain and satisfaction.

McDonald and Brown ${ }^{21}$ reported that women who underwent an operative vaginal birth, cesarean or perineal trauma (perineal tear or episiotomy) appear to delay sexual intercourse resumption. In the present study, all participants had a fixed partner and returned to sexual activity on average after 52 days after delivery in both groups (vaginal and cesarean). It is assumed that a stable relationship might be a facilitator for resumption of an active sex life, however, this did not guarantee a satisfactory sexual function, since more than half of the sample had FSFI score indicative of sexual dysfunction.

A limitation of this study is that perineal trauma was not divided into spontaneous perineal tears, episiotomy or others. As this was an online study and women have not been evaluated by a health professional, the adopted term "perineal trauma" aimed to reduce the risk of reporting errors.

The current study differed from previous studies because our investigation uses the online Brazilian version of FSFI for identifying female sexual function among Brazilian women on remote postpartum period according to the modes of delivery. Although similar studies have been developed internationally, in Brazil we do not have this kind of prior research to understand the particularities of our population. Furthermore, these findings may contribute for women to choose the mode of delivery based on real needs, since we demonstrated no difference in sexual function on postpartum between vaginal and cesarean delivery as it is the popular belief.

The design of this study was on the remote postpartum period. It is suggested that future longitudinal studies can evaluate women during pregnancy and postpartum in order to determine whether the type of delivery associated with other factors may influence on sexual function during puerperal pregnancy cycle. It is also important to carry out surveys with the partners, as they also experience intense changes with the arrival of parenthood that can influence the sexual function of the couple. Besides that, in order to evaluate the couple's sexual function, it may be relevant the adoption of health promotion measures.

Sexual dysfunction in remote postpartum period occurs in most women, since it was found frequently among the study participants. Sexual 
desire was the FSFI domain with lowest score, followed consecutively by pain, arousal, orgasm, lubrication and satisfaction. There were no significant differences in sexual function between modes of delivery. Our findings should be taken into

\section{References}

1. Asselmann E, Hoyer J, Wittchen H-U, Martini J. Sexual problems during pregnancy and after delivery among women with and without anxiety and depressive disorders prior to pregnancy: a prospective-longitudinal study. J Sexual Med. 2016; 13: 95-104.

2. Barbara G, Pifarotti P, Facchin F, Cortinovis I, Dridi D, Ronchetti C, Calzolari L, Vercellini P. Impact of mode of delivery on female postpartum sexual functioning: spontaneous vaginal delivery and operative vaginal delivery vs cesarean section. J Sexual Med. 2016; 13: 393-401.

3. Song M, Ishii H, Toda M, Tomimatsu T, Katsuyama H, Nakamura T, Nakai Y, Shimoya K. Association between sexual health and delivery mode. Sexual Med. 2014; 2 (4): 153-158.

4. Enderle, CF, Kerber NPC, Lunardi VL, Nobre CMG Mattos L, Rodrigues EF. Condicionantes e/ou determinantes do retorno à atividade sexual no puerpério. Rev Latino-Am Enferm. 2013; 21 (3).

5. Lipzschuetz M, Cohen SM, Liebergall-Wischnitzer M, Zbedat K, Hochner-Celnikier D, Lavy Y, Yagel S. Degree of bother from pelvic floor dysfunction in women one year after first delivery. Eur J Obstet Gynecol Reprod Biol. 2015; 191: 90-4

6. Dabrini F, Yabandeh AP, Shahi A, Kamjoo A, Teshnixi SH The effect of mode of delivery on postpartum sexual functioning in primiparous women. Oman Medical J. 2014; 29 (4): $276-9$.

7. Leal MC, da Silva AAM, Dias MAB, da Gama SGN, Rattner D, Moreira ME, Theme Flha MM, Domingues RMSM, Leite AJM, Cavalcante RS, Lansky S, Diniz CSG, Szwarcwald CL. Birth in Brazil: national survey into labour and birth. Reprod Health. 2012; 9: 15.

8. Hardy-Fairbanks AJ, Lauria MR, Mackenzie T, Mccarthy Jr M. Intensity and unpleasantness of pain following vaginal and cesarean delivery: a prospective evaluation. Birth. 2013; 40 (2): 125-33.

9. Spong CY, Berghella V, Westrom KD, Mercer BM, Saade GR. Preventing the first cesarean delivery: summary of a joint Eunice Kennedy Shriver National Institute of Child Health and Human Development, Society for MaternalFetal Medicine, and American College of Obstetricians and Gynecologists Workshop. Obstet Gynecol. 2012; 120 (5): 1181-1193.

10. Yeniel AO, Petri E. Pregnancy, childbirth, and sexual function: perceptions and facts. International Urologynecol J. 2014; 25: 5-14.

Received on May 12, 2017

Final version presented on December 26, 2017

Approved on April 2, 2018 account by health care professionals in order to design interventions that seek to promote the quality of sexuality and quality of life for postpartum women.

11. Latorre GFS, Bilck PA, Cardoso FL, Sperandio FF. Confiability and reliability of an on-line version of the Female Sexual Function Index by test-retest. Rev Bras Ginecol Obstet. 2013; 35 (10): 469-74.

12. Weigel M, Meston C, Rosen R. The Female Sexual Function Index (FSFI): cross-validation and development of clinical cutoff scores. J Sex Marital Ther. 2005; 31: 1-20.

13. Laganà AS, Burgio MA, Ciancimino L, Sicilia A, Pizzo A, Magno C, Butticè S, Triolo O. Evaluation of recovery and quality of sexual activity in women during postpartum in relation to the different mode of delivery: a retrospective analysis. Minerva Ginecol. 2015; 67 (4): 315-20.

14. Lurie S, Aizenberg M, Sulema V, Boaz M, Kovo M, Golan A, Sadan O. Sexual function after childbirth by the mode of delivery: a prospective study. Arch Gynecol Obstet. 2013; 288 (4): 785-92.

15. McDonald EA, Gartland D, Small R, Brown SJ Dyspareunia and childbirth: a prospective cohort study. BJOG. 2015; 122: 672-9.

16. Amiri FN, Omidvar S, Bakhtiari A, Yazdani S, Hajiahmadi M. Comparison of sexual function in primiparous women pre-pregnancy and postpartum: difference of the sexual function after the normal vaginal delivery and the cesarean section. Health. 2015; 7: 1379-86.

17. Qian R, Chen Z, Tang L, Zhang W. Postpartum adverse effects and sexual satisfaction following cesarean delivery in Beijing. Int J Gynecol Obstet. 2016; 132: 200-5.

18. Chang S-R, Chen K-H, Ho H-N, Lai Y-H, Lin M-I, Lee C$\mathrm{N}$, Lin WA. Depressive symptoms, pain, and sexual dysfunction over the first year following vaginal or cesarean delivery: a prospective longitudinal study. Int J Nurs Stud. 2015; 52: 1433-44.

19. Pardo DS, Lima RV, de Lima LMMR. Impact of pregnancy on female sexual function. Rev Bras Ginecol Obstet. 2013; 35 (5): $205-9$

20. Andreucci CB, Cecatti JG, Pacagnella RC, Silveira C, Parpinelli MA, Ferreira, EC, Angelini CR, Santos JP, Zanardi DM, Bussadori JC, Cecchino GN, Souza RT, Sousa $\mathrm{MH}$, Costa ML. Does severe maternal morbidity affect female sexual activity and function? Evidence from a Brazilian cohort study. PLoS ONE. 2015; 10 (12): 1-14.

21. McDonald EA, Brown SJ. Does method of birth make a difference to when women resume sex after childbirth? BJOG. 2013; 120: 823-30. 